\title{
The Association Between Body Mass Index and Dental Caries: Cross-Sectional Study
}

\author{
Khaled Alswat ${ }^{\mathrm{a}, \mathrm{c}}$, Waleed S. Mohamed ${ }^{\mathrm{a}}$, Moustafa A. Wahab ${ }^{\mathrm{b}}$, Ahmed A. Aboelil ${ }^{\mathrm{b}}$
}

\begin{abstract}
Background: Obesity is a growing health-related problem worldwide. Both obesity and dental caries are important health issues with multifactorial aspects. Some studies have shown an association between body mass index (BMI) and caries in childhood/adolescence but limited data about such an association are available in adults. The primary goal of this study was to assess the prevalence of dental caries and its relationship to BMI.
\end{abstract}

Methods: We conducted a cross-sectional study at Taif University Outpatient Clinic, for adults who had a visit to the dental clinic. Baseline characteristics were obtained by the participating physician. The decayed, missing, and filled teeth (DMFT) index was used to determine the prevalence of dental caries. Information about healthy eating, smoking, exercise, sleep patterns, media consumption, and brushing habits were collected.

Results: A total of 385 patients were enrolled with a mean age of 28.39 years, $72.8 \%$ were male, mean DMFT index score was 6.55 , and $85.5 \%$ reported brushing their teeth at least once daily. Of the participants, $55.3 \%$ were either overweight or obese, and $42.2 \%$ demonstrated a high prevalence of dental caries with no significant difference in BMI when compared to the low dental caries group.

Conclusions: A high prevalence of overweight/obesity and dental caries was observed among the participants. After controlling for potential confounders like smoking and brushing habits, significant positive correlation between BMI and DMFT was observed.

Keywords: Body mass index; Caries; DMFT; Habits; Obesity

Manuscript accepted for publication December 14, 2015

${ }^{a}$ Department of Internal Medicine, Taif University School of Medicine, Taif, Saudi Arabia

${ }^{b}$ Dental Clinic, Taif University School of Medicine, Taif, Saudi Arabia

${ }^{\mathrm{c} C}$ Corresponding Author: Khaled A. Alswat, Department of Internal Medicine,

Taif University School of Medicine, Taif, Saudi Arabia.

Email:kalswat@hotmail.com

doi: http://dx.doi.org/10.14740/jocmr2433w

\section{Introduction}

Obesity is defined as a condition of abnormal and excessive fat accumulation in adipose tissue to the extent that health may be adversely affected [1]. It is a global epidemic, and the World Health Organization (WHO) estimates that it is the fifth leading cause of mortality worldwide $[2,3]$. Obesity rates have doubled within the last 20 years in many developing and developed countries [4]. Moreover, it is a risk factor for many diseases such as type 2 diabetes, hypertension, hyperlipidemia, cerebrovascular diseases and certain types of cancers [5-8]. The rapid cultural and social changes that have occurred in the Gulf region since the discovery of oil and the subsequent economic boom of the 70s and 80s have been associated with an alarming increase in obesity [9-13]. There are many causes of obesity, but change in the region's diet quantity and quality is one of the major causes, as it has become more "westernized". The remarkable economic growth in Saudi Arabia has negatively affected the population's lifestyle [14]. Although there is a considerable amount of data on obesity prevalence rates, data on dietary habits and food consumption patterns are limited. Recent studies have revealed increasing consumption of animal products and refined foods at the expense of vegetables and fruits $[15,16]$. These dietary changes are considered to be one of the potential causes for the observed increase in the prevalence of both overweight and obesity among the Saudi population in the last few decades [17-20].

Dental caries is multi-factorial disease, and affects most of the world population. It is the primary cause of oral pain and tooth loss [21]. It is considered one of the major health-related problems in the young children and one of the most prevalent oral diseases. As a result of its high morbidity potential, this disease is now a main focus of the dental health profession. With its worldwide presence, both genders, all races, all socio-economic status, and all age groups are affected [22]. Because of the discomfort and the financial burden caused by dental caries, prevention is considered an important task for the health profession. Dental disease ranks as the second most expensive disease in Australia (second to cardiovascular disease) and absorbs 6.2\% of total recurrent expenditures in health, behind hospital services $(39.3 \%)$, medical services (18.7\%), and medications (14.0\%) [23]. Progress is achieved through scientific research that identifies best practices for treating and preventing dental caries.

A decline in dental caries prevalence in developed coun- 
tries has been observed over the past decades; however, addressing dental caries remains an unmet need for a significant proportion of the world's population [24, 25]. Recently, caries prevalence has increased in developing nations due to an array of factors, such as intake of sugary foods, low socio-economic status, exposure to fluorides, ethnicity, age, the limited access to oral health services and other lifestyle factors [26]. In 2003, the World Dental Federation, WHO and the International Association for Dental Research issued "Global Goals for Oral Health 2020". These goals provided guidance for local and national planners and policymakers to improve the oral health status of their populations [27].

Current research in dental medicine trends towards identifying the link between oral health and various systemic diseases. Previous studies have heightened the awareness among dentists about the connection between obesity and oral health in the young [28]. Hence the aim of this study is to assess the prevalence of dental caries, and to identify if there is any relationship between dental caries with age, body mass index (BMI), brushing frequency, dietary habits, physical activity, and smoking in Taif University population.

\section{Materials and Methods}

The study was conducted between June 2014 and May 2015 at Taif University Outpatient Clinics (TUOC), Saudi Arabia. There were no apparent issues that interfered with routine patient care under this protocol, and this study did not directly involve any treatment or intervention. The study included 385 male and female participants who were 18 years or older and who are willing to participate. Data were collected through interview and a self-report questionnaire. The prevalence of dental caries was obtained using the WHO standard criteria for dental caries diagnosis, namely the decayed, missing, and filled teeth (DMFT) index (range 1 - 18), to determine the total number of teeth or surfaces that are decayed, missing, or filled for each study participant. The clinical examination was performed by qualified dentists in sitting chairs in the dental clinic, using natural light and a light source if needed. Caps, masks, gloves, and gauze were used in accordance with infection control guidelines. Weight and height were measured and BMI was calculated according to the formula: weight $(\mathrm{kg}) /$ height $^{2}\left(\mathrm{~m}^{2}\right)$.

BMI was categorized into underweight $(\mathrm{BMI}<18.5)$, normal (BMI 18.5 - 24.9), overweight (BMI 25 - 30), and obese (BMI > 30). Information about relevant eating habits (i.e., consumption of soft drinks, fast food, and refined sugars), smoking, physical activity, and teeth brushing habits were collected. Brushing frequency was classified as $\geq 2$ times daily, once daily, many times weekly but not daily, and weekly or less. We also measured daily media consumption in hours, which included watching TV, using a computer, playing video games, and using a smart phone for entertainment.

\section{Statistical analysis}

Data were analyzed using the Statistical Package for Social
Table 1. Baseline Characteristics of the Whole Cohort

\begin{tabular}{|c|c|}
\hline \multicolumn{2}{|l|}{ Baseline characteristics } \\
\hline Mean age (years) & $28.39 \pm 11.4$ \\
\hline Male $(\%)$ & 72.8 \\
\hline Female $(\%)$ & 27.2 \\
\hline Hypertension (\%) & 10.2 \\
\hline Diabetes (\%) & 4.9 \\
\hline Mean body weight (kg) & $75.9 \pm 19.99$ \\
\hline Mean BMI $\left(\mathrm{kg} / \mathrm{m}^{2}\right)$ & $26.55 \pm 6.3$ \\
\hline Mean systolic blood pressure (mm Hg) & $122.86 \pm 15.2$ \\
\hline Mean diastolic blood pressure (mm Hg) & $77.23 \pm 8.92$ \\
\hline \multicolumn{2}{|l|}{ Dental health and care } \\
\hline Mean DMFT index $(1-18)$ & 6.55 \\
\hline Brushing teeth $\geq 2$ times/day (\%) & 67.3 \\
\hline Brushing teeth once daily (\%) & 18.2 \\
\hline Brushing teeth few times per week (\%) & 7.9 \\
\hline Brushing teeth weekly or less (\%) & 6.6 \\
\hline \multicolumn{2}{|l|}{ Special habits } \\
\hline Active smokers $(\%)$ & 8.1 \\
\hline Passive smokers (\%) & 13.6 \\
\hline Sedentary lifestyle (\%) & 47.1 \\
\hline Active $<100 \mathrm{~min} /$ week $(\%)$ & 36 \\
\hline Active $100-300 \mathrm{~min} /$ week (\%) & 11.3 \\
\hline Active $>300 \mathrm{~min} /$ week $(\%)$ & 5.6 \\
\hline Drinking soft drinks at least daily (\%) & 33.5 \\
\hline $\begin{array}{l}\text { Eating } 1 \text { serving of fruit/ } \\
\text { vegetables at least daily }(\%)\end{array}$ & 30.3 \\
\hline Media consumptions $<3$ h per day & $30.3 \%$ \\
\hline
\end{tabular}

Science software, version 20.0 (SPSS, Chicago, IL, USA). The Chi-square test was used to study the relationship between variables and to compare means. Multiple logistic regression analysis was used to determine the degree of association between obesity and dental caries and other variables.

\section{Results}

A total of 385 patients were enrolled in the study. The mean age was $28.39 \pm 11.44$ years, $72.8 \%$ were male, and the mean DMFT index was 6.55 . Of the patients, $67.3 \%$ reported brushing their teeth $\geq 2$ times per day, $18.2 \%$ brushed once daily, $7.9 \%$ brushed a few times per week, and $6.6 \%$ brushed weekly or less; $4.9 \%$ of the patients were diabetics, $10.2 \%$ were hypertensive, $8.1 \%$ were active smokers with mean duration of $1.24 \pm 1.24$ years, $13.6 \%$ reported exposure to passive smoke, $47.1 \%$ reported a sedentary lifestyle, $16.9 \%$ reported been active $\geq 100 \mathrm{~min} /$ week, $33.5 \%$ reported soft drinks at least once daily, $45.8 \%$ at least eat 1 serving/day of fruit/vegetables, and $30.3 \%$ consumed $<3 \mathrm{~h}$ of media/day (Table 1 ). 
Table 2. Baseline Characteristics Based on the Dental Caries Group

\begin{tabular}{|c|c|c|c|}
\hline & LDC group & HDC group & P value \\
\hline \multicolumn{4}{|l|}{ Baseline characteristics } \\
\hline Mean age (years) & 29.3 & 27.21 & 0.19 \\
\hline Male $(\%)$ & 74.89 & 70.89 & 0.411 \\
\hline Hypertension (\%) & 11.9 & 8.8 & 0.412 \\
\hline Diabetes $(\%)$ & 4.3 & 6.7 & 0.345 \\
\hline Mean body weight $(\mathrm{kg})$ & 75.38 & 76.9 & 0.87 \\
\hline Mean BMI $\left(\mathrm{kg} / \mathrm{m}^{2}\right)$ & 26.2 & 27.1 & 0.29 \\
\hline Mean systolic blood pressure (mm Hg) & 122.93 & 122.87 & 0.14 \\
\hline Mean diastolic blood pressure (mm Hg) & 76.54 & 77.93 & 0.067 \\
\hline \multicolumn{4}{|l|}{ Dental health and care } \\
\hline Mean DMFT index $(1-18)$ & 4.08 & 9.95 & $<0.01$ \\
\hline Brushing teeth $\geq 2$ times/day $(\%)$ & 66.2 & 68.9 & 0.122 \\
\hline Brushing teeth once daily (\%) & 18.52 & 18.35 & 0.366 \\
\hline Brushing teeth few times per week $(\%)$ & 7.9 & 8.23 & 0.35 \\
\hline Brushing teeth weekly or less (\%) & 7.4 & 4.4 & 0.38 \\
\hline \multicolumn{4}{|l|}{ Special habits } \\
\hline Active smokers $(\%)$ & 7.3 & 9.4 & 0.51 \\
\hline Passive smokers $(\%)$ & 13.8 & 13.2 & 0.23 \\
\hline Sedentary lifestyle (\%) & 46 & 48.4 & 0.57 \\
\hline Drinking soft drinks at least daily (\%) & 30.7 & 36.7 & 0.34 \\
\hline Eating 1 serving of fruit/vegetables at least daily (\%) & 38.9 & 54.78 & 0.002 \\
\hline Media consumptions $<3$ h per day & 29.5 & 31.84 & 0.353 \\
\hline
\end{tabular}

The mean body weight of the sample was $75.9 \pm 19.99 \mathrm{~kg}$. The mean BMI was $26.55 \pm 6.3 \mathrm{~kg} / \mathrm{m}^{2}$ with $6 \%$ of the sample being underweight, $31.4 \%$ were overweight, and $23.9 \%$ were obese. The mean systolic blood pressure (SBP) was $122.86 \mathrm{~mm} \mathrm{Hg}$, and the mean diastolic blood pressure (DBP) was $77.23 \mathrm{~mm} \mathrm{Hg}$. We divided the cohort into two groups based on the mean DMFT, so that those with mean DMFT $\geq 6.55$ were considered to be in the high dental caries group (HDC) and those with mean DMFT < 6.55 were considered to be in the low dental caries group (LDC). Of the sample, $57.9 \%$ were in the LDC group while $42.1 \%$ were in the HDC group. Compared to the HDC group, those in the LDC group were non-statically significantly older and had lower body weight/BMI, less likely to be diabetic, but more likely to be hypertensive. Although the LDC group had significantly lower mean DMFT, they also had worse overall brushing habits. The LDC group tended to have lower rates of active smoking, lower rates of daily soft drinks and a comparably sedentary lifestyle rate. HDC groups reported significantly higher rates of eating at least 1 serving of fruit/vegetables per day (Table 2).

Regarding cardiovascular markers, those in the LDC group tended to have non-statically significant lower DBP and comparable SBP. The groups were then divided based on their BMI into normal and overweight/obese. Overweight/obese patients tended to have non-significantly higher DMFT than normal weight patients (mean of 6.65 and 6.47, respectively, $\mathrm{P}=0.29)$, with non-significantly different brushing habits $(\mathrm{P}=$
0.44; Table 3). When comparing the cohort based on gender, the male mean BMI was 26.61 compared to 26.39 in females $(\mathrm{P}=$ 0.809 ), the mean DMFT for males was non-significantly lower (6.46 vs. $6.79, \mathrm{P}=0.38$ ), $9.7 \%$ of males were versus $3.8 \%$ of females $(\mathrm{P}=0.012)$, and both groups had similar brushing habits. We found a partial positive correlation between the BMI and mean DMFT $(\mathrm{P}=0.048)$, after controlling for diabetes, active smoking, passive smoking, teeth brushing, soft drinks and fruit consumption. However, there was no significant correlation between mean DMFT and media consumption, after controlling for BMI and the other important variables.

\section{Discussion}

Given that dental caries rates and BMI both measure diet-re-

Table 3. The Mean Decayed/Missing/Filled (DMF) According to BMI Categories

\begin{tabular}{lll}
\hline BMI categories & Mean BMI & Mean DMFT \\
\hline Underweight & 17.0 & 5.26 \\
Normal weight & 22.1 & 6.73 \\
Overweight & 27.19 & 6.42 \\
Obese & 34.64 & 6.48 \\
\hline
\end{tabular}


lated health outcomes; the association between the two is not surprising. Changes to lifestyle and diet since the mid-1990s, for example due to increased affluence and access to high caloric carbohydrate-rich foods and drinks, may help account for the rising prevalence in dental caries and obesity since that time period $[29,30]$. Our study showed that $42.1 \%$ of participants had high dental caries, in spite of the fact that $85.5 \%$ of the study population reported brushing their teeth at least once daily. HDC group were younger and more likely to have higher BMI, drink soda, be an active smoker, and to have sedentary lifestyle. They also had a higher diastolic blood pressure. However, not all studies have found a positive association between BMI and dental caries, as some studies suggest that there is no relationship and others show an inverse relationship [31, 32].

Recent national data from Sweden suggested a positive correlation between dental caries and BMI, and showed that obesogenic behavior such as snacking in early childhood predicted caries development in adolescence [33]. Our study was done in the adult population in Saudi Arabia and evaluated other risk factors for caries like smoking and sugary beverage drinking; even after adjusting for those variables, we found a positive correlation between BMI and dental caries prevalence. To our knowledge, there has been only one systematic review examining the relationship between obesity and dental caries [34]. This review included only seven studies published between 1984 and 2004, five of which only included a pediatric sample. Among them, one found a positive correlation between dental caries and BMI in a sample of 842 children aged $6-11$ years [35]. Another study found no correlation in a sample of over 5,000 three-year olds [36], while the third was not able to predict future dental caries experience on the basis of BMI status in more than 500 children (aged 5 - 13 years) [37]. Since the publication of this research [34], there has been a lack of studies that assessed the relationship between dental caries and BMI in the adult population in Saudi Arabia and more specifically in Taif city.

Dietary habits are significant contributors to obesity and dental caries epidemics. Changes in dietary pattern like increased consumption of soft drinks, fast food, and refined sugars have led to significant dietary changes among populations, and are considered to be common risk factors for obesity as well as dental caries. Given the strong evidence supporting the association of dental caries with irregular dietary patterns and quality and the fact that abnormal dietary intake has been linked to the development of obesity at a young age, a link between dental caries and body weight is biologically plausible [38]. When children watch a lot of TV, they tend to snack more frequently, particularly on foods that are high in fat and/ or sugar. This not only increases their overall caloric intake, which can lead to obesity, but it also increases their risk of developing tooth decay because the amount of time food is in contact with the teeth increases [32].

\section{Conclusion}

More than half of the participants were overweight or obese. Of the participants, $42.2 \%$ fell into the high dental caries group. Although the high caries group was generally younger, they had higher DBP and BMI. A significant positive correlation between BMI and DMFT was present, after controlling for the potential confounders like smoking, dietary habits, and brushing habits.

\section{Practical implications}

Dental caries and obesity share some common, modifiable influences such as diet and lifestyle including changes in physical activity and food characters. So obesity can be considered a predictor of dental caries and obese persons need more frequent dental examination and educational care.

\section{Limitation of the study}

Limitations include small sample size and data collection isolated to a single center. Larger studies with a multicenter approach are needed, as are studies with an intervention approach in order to establish causality, and there is need to identify associations and evaluate the weight of each variable as possible risk factors that may have a correlation if we were to have a larger sample size. However, study's strengths include evaluation of diet, sugary beverage drinking, smoking, and physical activities. We also evaluated some other newly identified potential causes for obesity like media consumption.

\section{Acknowledgement}

The authors would like to acknowledge the support of the management of Taif University who gave us support and help during our research.

\section{Conflict of Interests}

None.

\section{Funding}

None.

\section{References}

1. Obesity: preventing and managing the global epidemic. Report of a WHO consultation. World Health Organ Tech Rep Ser. 2000;894:i-xii, 1-253.

2. Alm A, Isaksson H, Fahraeus $\mathrm{C}$, Koch G, Andersson-Gare B, Nilsson M, Birkhed D, et al. BMI status in Swedish children and young adults in relation to caries prevalence. Swed Dent J. 2011;35(1):1-8.

3. Tripathi S, Kiran K, Kamala BK. Relationship between obesity and dental caries in children-A preliminary study. Journal of International Oral Health. 2010;2:65-72. 
4. Yang P, Zhou Y, Chen B, Wan HW, Jia GQ, Bai HL, Wu XT. Overweight, obesity and gastric cancer risk: results from a meta-analysis of cohort studies. Eur J Cancer. 2009;45(16):2867-2873.

5. Freedland SJ, Wen J, Wuerstle M, Shah A, Lai D, Moalej $\mathrm{B}$, Atala $\mathrm{C}$, et al. Obesity is a significant risk factor for prostate cancer at the time of biopsy. Urology. 2008;72(5):1102-1105.

6. Nguyen NT, Magno CP, Lane KT, Hinojosa MW, Lane JS. Association of hypertension, diabetes, dyslipidemia, and metabolic syndrome with obesity: findings from the National Health and Nutrition Examination Survey, 1999 to 2004. J Am Coll Surg. 2008;207(6):928-934.

7. Abbasi F, Brown BW, Jr., Lamendola C, McLaughlin T, Reaven GM. Relationship between obesity, insulin resistance, and coronary heart disease risk. J Am Coll Cardiol. 2002;40(5):937-943.

8. Musaiger AO, Al-Mannai MA. Weight, height, body mass index and prevalence of obesity among the adult population in Bahrain. Ann Hum Biol. 2001;28(3):346-350.

9. Al-Kandari YY. Prevalence of obesity in Kuwait and its relation to sociocultural variables. Obes Rev. 2006;7(2):147-154.

10. Carter AO, Saadi HF, Reed RL, Dunn EV. Assessment of obesity, lifestyle, and reproductive health needs of female citizens of Al Ain, United Arab Emirates. J Health Popul Nutr. 2004;22(1):75-83.

11. Al-Riyami AA, Afifi MM. Prevalence and correlates of obesity and central obesity among Omani adults. Saudi Med J. 2003;24(6):641-646.

12. Alsaif MA, Hakim IA, Harris RB, Alduwaihy M, AlRubeaan K, Al-Nuaim AR, Al- Attas OS. Prevalence and risk factors of obesity and overweight in adult Saudi population. Nutrition Research. 2002;22:1243-1252.

13. Gasbarrini A, Piscaglia AC. A natural diet versus modern Western diets? A new approach to prevent "well-being syndromes". Dig Dis Sci. 2005;50(1):1-6.

14. Amin TT, Al-Sultan AI, Ali A. Overweight and obesity and their relation to dietary habits and socio-demographic characteristics among male primary school children in Al-Hassa, Kingdom of Saudi Arabia. Eur J Nutr. 2008;47(6):310-318.

15. Mahfouz AA, Abdelmoneim I, Khan MY, Daffalla AA, Diab MM, Al-Gelban KS, Moussa H. Obesity and related behaviors among adolescent school boys in Abha City, Southwestern Saudi Arabia. J Trop Pediatr. 2008;54(2):120-124.

16. al-Nuaim AA, Bamgboye EA, al-Rubeaan KA, al-Mazrou Y. Overweight and obesity in Saudi Arabian adult population, role of socio-demographic variables. J Community Health. 1997;22(3):211-223.

17. Al-Nozha MM, Al-Mazrou YY, Al-Maatouq MA, Arafah MR, Khalil MZ, Khan NB, Al-Marzouki K, et al. Obesity in Saudi Arabia. Saudi Med J. 2005;26(5):824-829.

18. Al-Hazzaa HM. Rising trends in BMI of Saudi adolescents: evidence from three national cross sectional studies. Asia Pac J Clin Nutr. 2007;16(3):462-466.

19. El-Hazmi MA, Warsy AS. A comparative study of prevalence of overweight and obesity in children in different provinces of Saudi Arabia. J Trop Pediatr. 2002;48(3):172177.

20. Fejerskov O, Kidd E, Nyvad B. Dental Caries: The Disease and Its Clinical Management. 2nd ed. Oxford: Blackwell Munksgaard; 2008.

21. Prakash H, Sidhu SS, Sundaram KR. Prevalence of Dental Caries among delhi school chidren. Journal of Indian Dental Association.1999;70:12-14.

22. Australian Institute of Health and Welfare: Australia's health 2010. Australians health series no. 12. Canberra: AIHW; 2010. Cat. No AUS 122.

23. World Health Organization, 1981. Oral Health Information Systems. Geneva: World Health Organization. Accessed August 27, 2012.

24. Petersen PE, Bourgeois D, Ogawa H, Estupinan-Day S, Ndiaye C. The global burden of oral diseases and risks to oral health. Bull. WHO. 2005;83:661-669.

25. World Health Organization, 1997. Oral Health SurveysBasic Methods, fourth ed. World Health Organization, Geneva.

26. Hobdell M, Petersen PE, Clarkson J, Johnson N. Global goals for oral health 2020. Int Dent J. 2003;53(5):285-288.

27. Huang JS, Becerra K, Walker E, Hovell MF. Childhood overweight and orthodontists: results of a survey. J Public Health Dent. 2006;66(4):292-294.

28. Vann WF, Jr., Bouwens TJ, Braithwaite AS, Lee JY. The childhood obesity epidemic: a role for pediatric dentists? Pediatr Dent. 2005;27(4):271-276.

29. Booth ML, Dobbins T, Okely AD, Denney-Wilson E, Hardy LL. Trends in the prevalence of overweight and obesity among young Australians, 1985, 1997, and 2004. Obesity (Silver Spring). 2007;15(5):1089-1095.

30. Dye BA, Shenkin JD, Ogden CL, Marshall TA, Levy SM, Kanellis MJ. The relationship between healthful eating practices and dental caries in children aged 2-5 years in the United States, 1988-1994. J Am Dent Assoc. 2004;135(1):55-66.

31. Sanchez-Perez L, Irigoyen ME, Zepeda M. Dental caries, tooth eruption timing and obesity: a longitudinal study in a group of Mexican schoolchildren. Acta Odontol Scand. 2010;68(1):57-64.

32. Kantovitz KR, Pascon FM, Rontani RM, Gaviao MB. Obesity and dental caries--A systematic review. Oral Health Prev Dent. 2006;4(2):137-144.

33. Armfield JM, Roberts-Thomson KF, Spencer AJ. Dental Statistics and Research Series: The Child Dental Health Survey, Australian 1999: Trends across the 1990s. Cat. no. DEN 95: AIHW; 2003.

34. Willershausen B, Haas G, Krummenauer F, Hohenfellner K. Relationship between high weight and caries frequency in German elementary school children. Eur J Med Res. 2004;9(8):400-404.

35. Chen W, Chen P, Chen SC, Shih WT, Hu HC. Lack of association between obesity and dental caries in three-yearold children. Zhonghua Min Guo Xiao Er Ke Yi Xue Hui Za Zhi. 1998;39(2):109-111.

36. Tuomi T. Pilot study on obesity in caries prediction. Community Dent Oral Epidemiol. 1989;17(6):289-291.

37. Pinto A, Kim S, Wadenya R, Rosenberg H. Is there an as- 
sociation between weight and dental caries among pediatric patients in an urban dental school? A correlation study. J Dent Educ. 2007;71(11):1435-1440.

38. Alm A, Fahraeus C, Wendt LK, Koch G, Andersson-
Gare B, Birkhed D. Body adiposity status in teenagers and snacking habits in early childhood in relation to approximal caries at 15 years of age. Int J Paediatr Dent. 2008;18(3):189-196. 